\title{
Elastomers three-dimensional biomodels proven to be a trustworthy representation of the angiotomographic images
}

\author{
Biomodelos tridimensionais de elastômero provaram ser uma representação confiável de \\ imagens angiotomográficas
}

\author{
André Giacomelli Leal', Leonardo Brancia Pagnan², Raphael Teruaki Kondo², José Aguiomar Foggiatto³, \\ Guilherme José Agnoletto ${ }^{4}$, Ricardo Ramina ${ }^{4}$
}

\begin{abstract}
Intracranial aneurysm (IA) rupture is responsible for $80 \%$ of spontaneous arachnoid hemorrhages and associated with an extremely high mortality rate. Two possible surgical interventions are endovascular embolization and microsurgical clipping. Three-dimensional (3D) prototyping models help in surgical planning minimizing perioperative risks in both methods and reducing operating time. Methods: 3D biomodels were printed with flexible material (elastomer) using angiotomographic DICOM acquired images and compared to 3D digital subtraction angiography (DSA) images. Results: 3D biomodels represented the aneurysm angioarchitecture exactly, especially the neck and domus features. Conclusion: Elastomers 3D biomodels proved to be a trustworthy representation of the angiotomographic images and could be used to help surgical planning in IA treatment.
\end{abstract}

Keywords: intracranial aneurysm; models, anatomic; elastomers, microsurgery.

\section{RESUMO}

A ruptura dos aneurismas intracranianos é responsável por $80 \%$ das hemorragias subaracnóideas espontâneas e está associada a uma taxa de mortalidade extremamente alta. Duas intervenções cirúrgicas viáveis são embolização endovascular e clipagem microcirúrgica. Os modelos de prototipagem tridimensional (3D) auxiliam no planejamento cirúrgico e na diminuição dos riscos intra-operatórios nos dois procedimentos e redução do tempo da cirurgia. Métodos: Foram impressos biomodelos em 3D com material flexível (elastômero) utilizando imagens DICOM de angiotomografia e comparados com imagens de angiografia por subtração digital em 3D (DAS). Resultados: Biomodelos em 3D representam com exatidão a angioarquitetura do aneurisma, particularmente os detalhes do colo e domus. Conclusão: Biomodelos em 3D com elastômeros mostraram ser uma representação confiável das imagens angiotomográficas, podendo ser utilizados no planejamento cirúrgico no tratamento de IA.

Palavras-chave: aneurisma intracraniano; modelos anatômicos; elastômeros; microcirurgia.

Intracranial aneurysms (IA) are abnormal dilatations that can arise in any blood vessels of the intracranial circulation due to histopathological and hemodynamic alterations. It is estimated that $6 \%$ of people worldwide present with a non-ruptured IA. Risk factors for IA include family history, hereditary disorders predisposing aneurysm formation, age (younger than 50 years old), gender (female), tobacco and cocaine consumption ${ }^{1}$.

An extremely high mortality rate, associated with IA rupture, occurs in approximately $2 \%$ of the cases and is responsible for $80 \%$ of all spontaneous subarachnoid hemorrhages $^{2}$. Aneurysms larger than $10 \mathrm{~mm}$ or located in the posterior circulation present an even higher risk of rupture. Therefore, it is fundamental to offer the best treatment option for a diagnosed IA.

Two options for surgical treatment of an IA are available: endovascular embolization and microsurgical clipping $^{3}$, both aiming to exclude the aneurysm from the cerebral circulation. Endovascular embolization is

${ }^{1}$ Instituto de Neurologia de Curitiba - INC , Divisão de Neurocirurgia Vascular, Curitiba PR, Brasil;

${ }^{2}$ Faculdade Evangélica do Paraná, Faculdade de Medicina, Curitiba PR, Brasil;

${ }^{3}$ Universidade Tecnológica Federal do Paraná - UTPFR, Divisão de Prototipagem Rápida, Curitiba PR, Brasil;

4 Instituto de Neurologia de Curitiba - INC, Departamento de Neurocirurgia, Curitiba PR, Brasil.

Correspondence: André Giacomelli Leal; Instituto de Neurologia de Curitiba (INC), Divisão de Neurocirurgia Vascular; Rua Jeremias Maciel Perretto, 300 ; 81210-310 Curitiba PR, Brasil; E-mail: andregiacomelli@ibest.com.br

Conflict of interest: There is no conflict of interest to declare.

Received 15 March 2016; Received in final form 09 June 2016; Accepted 13 June 2016. 
generally performed with platinum coils to fill the aneurysm, whether by remodeling stent-assisted or not. Microsurgical clipping uses a titanium clip that occludes the aneurysm neck.

Microsurgical clipping was notably the only reliable treatment for IA in previous decades before the advent of the endovascular techniques. Currently, a great variety of IAs are treated with embolization. Nevertheless some complex cases still make embolization a less than viable method, requiring classic microsurgical clipping.

In order to better choose between the surgical techniques and the best strategies to use within each one, surgeons often rely on various imaging methods. Cerebral computed tomography angiography (CTA) is a reliable non-invasive imaging method that can reach specificity levels as high as $100 \%$ as well as a sensitivity of $95 \%$ for evaluation of IAs, although Digital Subtraction Angiography (DSA) remains the gold standard.

The restraint to these methods is the fact that they present the vessels structures in a two-dimensional (2D) pattern, limiting visualization of aneurysmal neck and adjacent vessels that must be carefully studied ${ }^{4}$. Even the most recent 3D CTAs and DSAs end up printed on paper, which ultimately is a $2 \mathrm{D}$ media.

One of the main features of microsurgical clipping that must be carefully evaluated is the choice of adequate clip and material, bearing in mind the large anatomic variability that can be encountered. In cases of widened neck or complex IA, the preoperative surgical planning is imperative to avoid extending operative time ${ }^{5}$, excessive manipulation of adjacent vessels and increased hemorrhage risk ${ }^{6}$.

With those risks in mind, several studies have been developed with 3D IA models, to enable familiarization and preoperative planning with the aneurysm anatomy and the angioarchitecture ${ }^{7}$.

Two combined techniques have resulted in biomedical prototyping models: rapid prototyping (RP) and image acquisition (integrating reconstruction). Prototyping is a manufacturing process that allows the production of models from stereolithography archives. The manufacturing process consists of successive layers of various, currently existing, polymeric materials. Several technologies use a wide range of polymeric and metallic materials that can be found as powder, liquid or solid filaments. These processes are a method of additive manufacturing. The most frequently-used process today is the Polyjet, which produces prototypes through polymerization using ultraviolet light and thin layers of acrylic resin successively jetted on top of each other.

In light of RP technologies and the non-invasive imaging methods that are available today, the biomedical models can aid surgical planning of several pathologies, as they can be found diversely in the literature ${ }^{8,9}$. However there are still few studies evaluating RP for analysis of $\mathrm{IAs}^{10,11,12}$.

\section{METHODS}

The study consisted of two stages. In the first, two patients with non-ruptured IAs, who consented to take part in the study, were selected. Both underwent CTA imaging. The images were generated in DICOM (Digital Imaging and Communication in Medicine) format and processed by two types of specialized software: InVesalius (Figure 1) and CATIA (Figures 2, 3 and 4). Subsequently the IA biomodels were printed with a specific $3 \mathrm{D}$ printer (Object Conmex $350^{\circ}$ ). The prototypes were made of a flexible acrylic resin called elastomer (TangoBlackPlus ${ }^{\bullet}$ ), which can return to its original shape even after being deformed, compressed or stretched. The prototyping was performed at the Renato Archer Center of Technology and Information, in São Paulo, Brazil.

In the second stage of the study, the malleable prototypes that had been created previously were compared with DSA

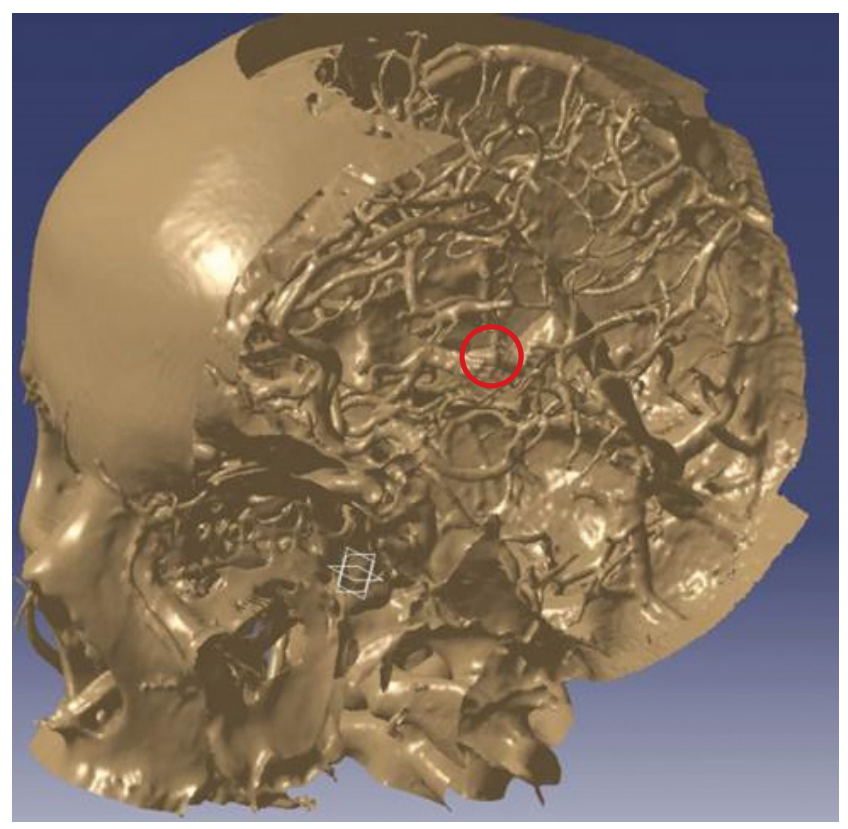

Source: Núcleo de Prototipagem e Ferramental (NUFER - UTFPR)

Figure 1. Image from InVesalius Software, highlighting the aneurysm.



Figure 2. Segmented image from patient \#1, middle cerebral artery (arrow). 
images of the same patients, aiming to confirm compatibility of morphology and angioarchitecture. It was imperative that complete correlation of the aneurysm morphology was achieved as it is essential information for the biomodel validation.

\section{RESULTS}

At the end of the first stage, four 3D elastomer models were made (two models of each aneurysm) to represent the exact shape of the aneurysm in real dimension and size. Model 1 (Figure 2) shows a medium cerebral artery IA, measuring $8 \times 5 \mathrm{~mm}$. Model 2 (Figure 3) shows a posterior communicating artery IA, measuring $7 \times 6 \mathrm{~mm}$. The four models were produced at the same time (18.5 grams of material), with a cost of U\$ 9.39 each. The Center of Technology and Information provided the prototypes without any costs and delivered them in seven days.

In the second stage, the real-size prototypes were validated as perfect copies of the IA morphology when compared to

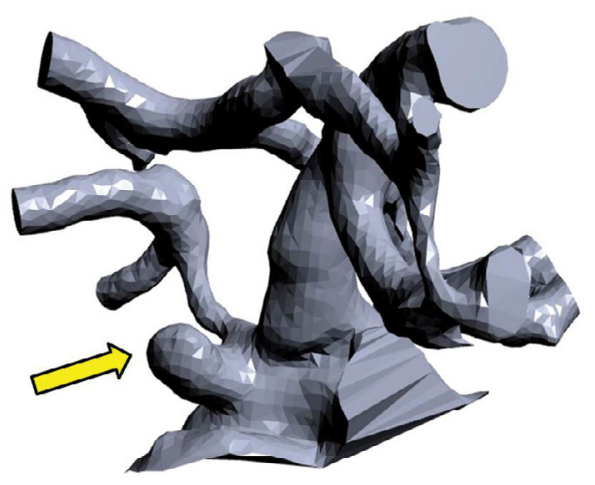

Figure 3. Segmented image from patient \#2, posterior communicating artery (arrow). their respective DSAs (Figure 5). The aneurysmal necks were precisely recreated in real size.

\section{DISCUSSION}

Previous literature has suggested the possibility of producing 3D models for simulation of IA surgery, either microsurgery or endovascular techniques. Rapid prototyping has also been produced in other areas of healthcare, such as in dentistry and vascu-



Erbano et al. ${ }^{16}$ demonstrated the feasibility of making IA 3D models using a non-flexible acrylic resin (FullCure $720^{\circ}$ ) with the RP method. Four patients were selected with aneurysms in the most common locations and the biomodels compared to the respective patients' DSA images, demonstrating that the IA morphology was precisely represented. However, the resin that was used lacked elastic properties to emulate the consistency of the aneurysm.

In the present study, flexible biomodel manufacturing was possible, which could be helpful during surgery planning or pre-operation aneurysm clipping simulation.

The main advantage of IA biomodels is that they allow surgeons to plan ahead and even practice the procedure prior to performing it, as it even gives the opportunity to choose an appropriate metallic clip, thus reducing operating time, vessel manipulation and risk of complications. As the field of view during an operation is restricted to the surgical access and craniotomy performed, it is not uncommon to find it difficult to see the structures surrounding the aneurysm, such as adjacent vessels. This is yet another feature in which 3D biomodels can help surgery planning ${ }^{11,12,17}$.

D’Urso et al. ${ }^{10}$ were the first to apply the technology of designing IA 3D models using angiotomography. Later, Wurm et al. improved the technique by using 3D rotational CTAs to produce models with higher image resolution ${ }^{12}$. The technological


Source: Núcleo de Prototipagem e Ferramental (NUFER - UTFPR)

Figure 4. Isolated aneurysms in patients \#1 and \#2, respectively, in stereolithographic shape (arrows). 


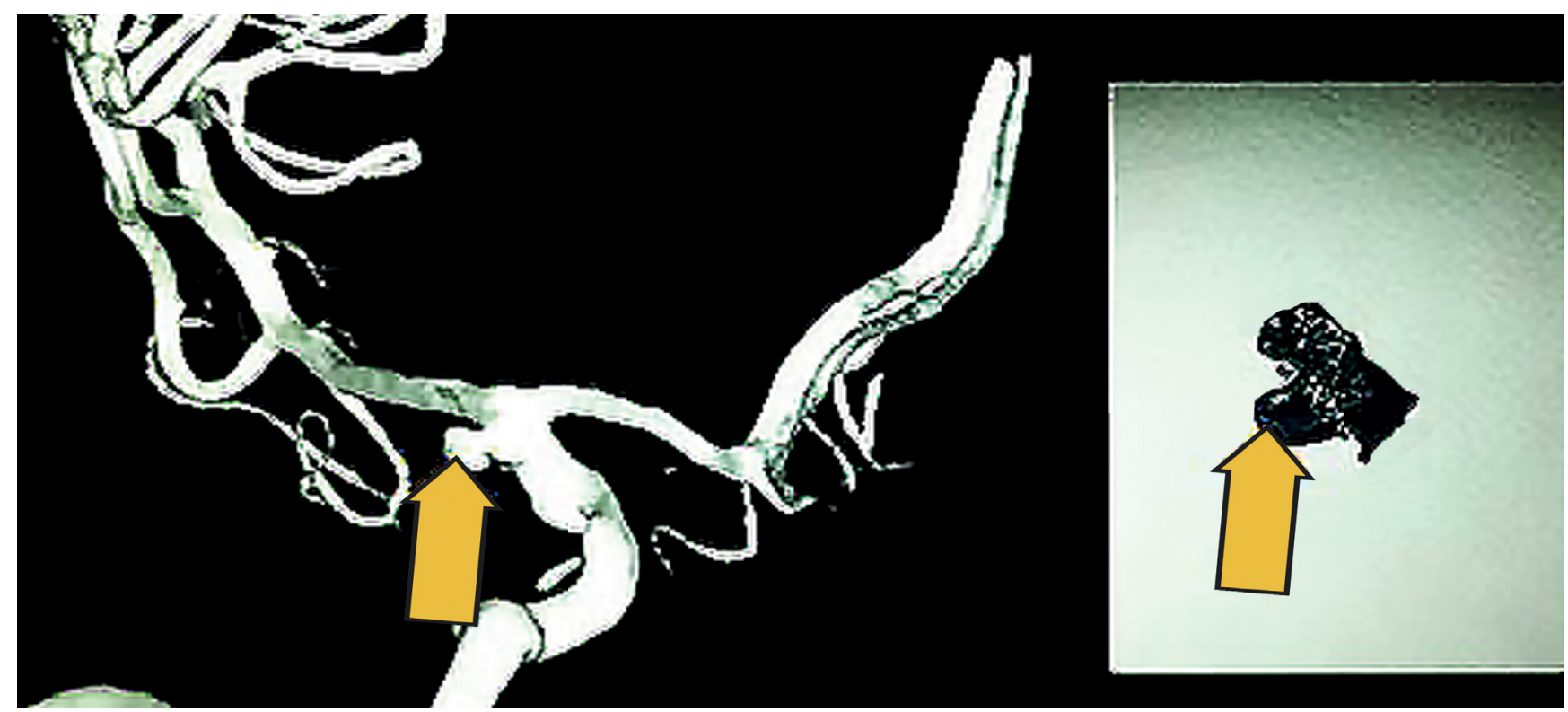

Figure 5. DSA reconstruction and prototype being compared (arrows). Source: DSA of patient \#2 and photo by the authors.

advances resulted in the design of more accurate printers, with fewer cuts and production of more evolved models.

When it comes to the use of 3D models in endovascular surgery, Chueh et al. and Wetzel et al. demonstrated the possibility of creating prototypes with lumen replication and representation, creating extremely malleable models ${ }^{7,18}$.

Another important feature of IA prototypes is that they allow a more precise explanation of the procedure proposed to the patient, with a visual and touchable media, facilitating the patient's and the family's understanding of the disease and treatment. Even surgeons feel more confident when they are familiar with the complete, real-size anatomy and morphology of the aneurysm to be operated on ${ }^{11,12}$.

There are still some limitations concerning the future production of IA prototypes. For example, the models cannot yet represent the presence of a pre-existing intra-arterial thrombus or how thick the wall of an aneurysm is. In cases of ruptured aneurysms, the production of prototypes is not viable due to the long period of time required for the completion of the whole process. It is expected that, in the future, new techniques and technologies of $3 \mathrm{D}$ printing will make it possible to produce RP models even in urgent situations.

In conclusion, it is possible to produce elastomer IA prototypes by means of rapid prototyping. The models have proved to be a faithful reproduction of the CTA. Their flexible material can be used for preoperative planning and simulation of surgical strategies, despite not having the elasticity of the actual vessel wall. It is expected that future studies will improve the prototyping technique and apply it to a larger number of patients with non-ruptured IAs.

\section{References}

1. Vega C, Kwoon JV, Lavine SD. Intracranial aneurysms: current evidence and clinical practice. Am Fam Physician. 2002;66(4):601-8.

2. Suarez JI, Tarr RW, Selman WR. Aneurysmal subarachnoid hemorrhage. N Engl J Med. 2006;354(4):387-96. doi:10.1056/NEJMra052732

3. Li H, Pan R, Wang H, Rong X, Yin Z, Milgrom DP et al. Clipping versus coiling for ruptured intracranial aneurysms: a systematic review and meta-analysis. Stroke. 2013;44(1):29-37. doi:10.1161/STROKEAHA.112.663559

4. Guglielmi G, Viñuela F, Duckwiler G, Dion J, Lylyk P, Berenstein A et al. Endovascular treatment of posterior circulation aneurysms by electrothrombosis using electrically detachable coils. J Neurosurg. 1992;77(4):515-24. doi:10.3171/jns.1992.77.4.0515

5. Lawton MT, Spetzler RF. Surgical management of giant intracranial aneurysms: experience with 171 patients. Clin Neurosurg. 1995;42:245-66.

6. Rinne J, Hernesniemi J, Niskanen M, Vapalahti M. Management outcome for multiple intracranial aneurysms. Neurosurgery. 1995;36(1):31-7. doi:10.1227/00006123-199501000-00003
7. Chueh JY, Wakhloo AK, Gounis MJ. Neurovascular modeling: small-batch manufacturing of silicone vascular replicas. AJNR Am J Neuroradiol. 2009;30(6):1159-64. doi:10.3174/ajnr.A1543

8. Müller A, Krishnan KG, Uhl E, Mast G. The application of rapid prototyping techniques in cranial reconstruction and preoperative planning in neurosurgery. J Craniofac Surg. 2003;14(6):899-914. doi:10.1097/00001665-200311000-00014

9. Winder J, Bibb R. Medical rapid prototyping technologies: state of the art and current limitations for application in oral and maxillofacial surgery. J Oral Maxillofac Surg. 2005;63(7):1006-15. doi:10.1016/j.joms.2005.03.016

10. D'Urso PS, Thompson RG, Atkinson RL, Weidmann MJ, Redmond MJ, Hall BI et al. Cerebrovascular biomodelling: a technical note. Surg Neurol. 1999;52(5):490-500. doi:10.1016/S0090-3019(99)00143-3

11. Kimura T, Morita A, Nishimura K, Aiyama $\mathrm{H}$, Itoh $\mathrm{H}$, Fukaya $S$ et al. Simulation of and training for cerebral aneurysm clipping with 3-dimensional models. Neurosurgery. 2009;65(4):719-25. doi:10.1227/01.NEU.0000354350.88899.07 
12. Wurm G, Tomancok B, Pogady P, Holl K, Trenkler J. Cerebrovascular stereolithographic biomodeling for aneurysm surgery. Technical note. J Neurosurg. 2004;100(1):139-45. doi:10.3171/jns.2004.100.1.0139

13. Khan IS, Kelly PD, Singer RJ. Prototyping of cerebral vasculature physical models. Surg Neurol Int. 2014;5(1):11. doi:10.4103/2152-7806.125858

14. Kono K, Shintani A, Okada H, Terada T. Preoperative simulations of endovascular treatment for a cerebral aneurysm using a patient-specific vascular silicone model. Neurol Med Chir (Tokyo). 2013;53(5):347-51. doi:10.2176/nmc.53.347

15. Sugiu K, Martin JB, Jean B, Gailloud P, Mandai S, Rufenacht DA. Artificial cerebral aneurysm model for medical testing, training, and research. Neurol Med Chir (Tokyo). 2003;43(2):69-72. doi:10.2176/nmc.43.69
16. Erbano BO, Opolski AC, Olandoski M, Foggiatto JA, Kubrusly LF, Dietz UA et al. Rapid prototyping of three-dimensional biomodels as an adjuvant in the surgical planning for intracranial aneurysms. Acta Cir Bras. 2013;28(11):756-61. doi:10.1590/S0102-86502013001100002

17. Wurm G, Lehner M, Tomancok B, Kleiser R, Nussbaumer K. Cerebrovascular biomodeling for aneurysm surgery: simulation-based training by means of rapid prototyping technologies. Surg Innov. 2011;18(3):294-306. doi:10.1177/1553350610395031

18. Ohta M, Hirabayashi M, Wetzel S, Lylyk P, Wata H, Tsutsumi S et al. Impact of stent design on intra-aneurysmal flow: a computer simulation study. Interv Neuroradiol. 2004;10(2 Suppl):85-94. doi:10.1177/15910199040100S216 